\section{Teóricos e pesquisadores de rádio no Brasil}

Nair PRATA ${ }^{1}$

Izani MUSTAFA ${ }^{2}$

Sônia Caldas PESSOA ${ }^{3}$

Resumo: A presente pesquisa apresenta um levantamento da produção acadêmica sobre o rádio no Brasil. O objetivo é reunir o trabalho de pesquisadores e teóricos que colaboram tanto para pensar o rádio enquanto objeto de estudo, quanto para consolidar um campo teórico que tenha a radiofonia como temática principal. Para tal, foram identificados e analisados trabalhos apresentados nos principais congressos nacionais de comunicação como Intercom, SBPJor, Rede Alcar e Compós. Também foram mapeadas as dissertações e as teses publicadas no Portal Capes (1987-2010) e livros publicados que têm o rádio como objeto principal.

Palavras-chave: $\quad$ RÁDIO; $\quad$ TEÓRICOS;
PESQUISADORES.

\section{Teóricos e investigadores de radio en Brasil}

Resumen: La presente investigación presenta un levantamiento de la producción académica sobre el radio en Brasil. El objetivo es reunir el trabajo de investigadores y teóricos que colaboran tanto para pensar el radio mientras objeto de estudio, cuanto para consolidar un campo teórico que tenga la radiofonia como temática principal. Para tal, fueron identificados y analizados trabajos presentados en los principales congresos nacionales comunicacionales como Intercom, SBPJor, Rede Alcar y Compós. También fueron mapeadas las dissertações y las tesis publicadas en el Portal Capes (1987-2010) y libros publicados que tienen el radio como objeto principal.

Palabras clave: RADIO, TEÓRICOS; INVESTIGADORES.

1 Professora adjunta da Universidade Federal de Ouro Preto (UFOP), jornalista e doutora em Linguística Aplicada.nairprata@uol.com.br 2Doutoranda em Comunicação (PUCRS), mestre em História do Tempo Presente (Udesc), jornalista e coordenadora da Rádio Joinville Cultural FM (105.1).izani@brturbo.com.br

3 Doutoranda em Linguística (UFMG), mestre em Linguística, jornalista e professora de Comunicação.soniapessoa@hotmail.fr
O rádio, que completou 90 anos de existência no Brasil - considerando como referência a primeira transmissão oficial no país, em 7 de setembro de 1922, durante as comemorações do centenário da Independência - vem sendo cada vez mais escolhido como objeto de estudo por pesquisadores de comunicação, história, sociologia e várias outras áreas do conhecimento. Em todos os congressos nacionais e regionais de comunicação se verifica a presença de pesquisadores que apresentam trabalhos sobre o rádio com diferentes abordagens. O crescimento e o interesse em pesquisar o rádio têm aumentado e os motivos para isso certamente incluem a proliferação dos cursos de pós-graduação em Comunicação. O baixo interesse em relação a este meio de comunicação ficou para trás e, como salienta Moreira (2003), “o rádio representa, por motivos variados, um dos segmentos mais vivos da mídia, entre os quais se destaca a sua maleabilidade, entendida aqui como a capacidade de se adaptar a momentos e situações distintos" (p. 10). A concentração das pesquisas ainda é na Região Sudeste do país, mas, aos poucos, investigadores de outras regiões começam a apresentar novos estudos, levantamentos e mapeamentos importantes para o entendimento da radiofonia. A produção bibliográfica sobre o rádio também tem aumentado, possibilitando a ampliação do conhecimento sobre as teorias e as pesquisas. $\mathrm{Na}$ investigação realizada por este trabalho, por exemplo, elencamos 208 livros de autores brasileiros que têm o rádio como objeto principal.

\section{Breve histórico da pesquisa em rádio no Brasil}

Alguns pesquisadores têm envidado esforços com vistas a identificar, mapear e analisar a produção acadêmica sobre o rádio no Brasil. A maior parte deles recorta um período ou um estado brasileiro para a realização da pesquisa. Moreira (1991) se ocupou do levantamento dos livros publicados até 1990; como resultado foi produzido o livro O rádio no Brasil. Em parceria com Del Bianco, Moreira (1999) identificou 21 livros sobre o rádio nas décadas de 1980 e 1990. Del Bianco, por sua vez, em trabalho conjunto com Zuculoto (1996) relacionou os artigos apresentados no Grupo de Rádio da Intercom em seus primeiros anos. Prata (2011) apresentou um balanço da produção nos 20 anos do mesmo grupo.

Haussen (2004) analisou um período de dez anos - 1991/2001 - da produção bibliográfica nacional sobre rádio a partir do levantamento de livros, artigos, dissertações e teses, identificando a origem e a preponderância dos temas. Entre as pesquisas regionais podemos citar Klöckner (2008), que abordou as dissertações 
e teses gaúchas sobre o rádio, e Prata, em conjunto com Moura, Pessoa, Campelo e Fialho (2011), que incursionaram pelo universo dos estudos sobre rádio nas instituições de ensino superior de Belo Horizonte.

Ao mapear os artigos publicados nos anos de 2003 e 2004 nos grupos de pesquisa em jornalismo da Intercom, SBPJor e Compós, Meditsch e Segala (2005) identificaram 263 textos. O rádio representa apenas $2,7 \%$ dos meios estudados sendo superado pelo jornal $(33,5 \%)$, internet $(13,7 \%)$, televisão $(8,7 \%)$ e revista $(5,3)$. São menos representativos que o rádio do ponto de vista quantitativo nessa pesquisa a webradio $(1,9 \%)$, webTV $(1,1 \%)$ e outros $(1,2 \%)$.

Nosso desafio, neste trabalho, consiste em ampliar a pesquisa sobre o espaço ocupado pelo rádio nos estudos acadêmicos brasileiros. Para tal, nos valemos de diversas fontes de pesquisa. Para identificar os artigos recorremos aos anais de todos os congressos de Comunicação Social realizados por quatro importantes entidades: Associação Nacional dos Programas de Pós-Graduação em Comunicação (Compós), Sociedade Brasileira de Estudos Interdisciplinares da Comunicação (Intercom), Associação Brasileira de Pesquisadores de História da Mídia (Alcar) e Sociedade Brasileira de Pesquisadores em Jornalismo (SBPJor). O primeiro ano da pesquisa, no caso dos artigos, é 1991, quando foi criado o Grupo de Rádio da Intercom, e o último é 2011.

A identificação e a análise das dissertações e teses foram realizadas a partir de pesquisas científicas publicadas no Portal Capes, no período de 1987 a 2010. A busca foi realizada pelas palavras-chave "rádio", "radiojornalismo" e "história do rádio" e levou em conta produções de trabalhos das áreas de conhecimento da Comunicação e de outras como História, Artes, Sociologia e Educação, que contivesse em seu conteúdo fundamentação teórica na comunicação e/ou tivesse estudado o rádio por um diferente aspecto.

Já no caso dos livros, partimos de um levantamento realizado pelas professoras Débora Cristina Lopez e Izani Mustafá, para o Grupo de Pesquisa Rádio e Mídia Sonora da Intercom, em 2010. Para este trabalho, a pesquisa foi atualizada e ampliada.

\section{Teóricos e pesquisadores de rádio no Brasil}

Com o objetivo de conhecer e identificar os principais teóricos e pesquisadores de rádio no Brasil, foi realizada pesquisa a partir do seguinte corpus:

- Trabalhos apresentados no GP Rádio e Mídia Sonora, nos congressos da Intercom, de
1991 a 2010

- Trabalhos apresentados no GT História do Rádio, nos encontros da Rede Alcar, de 2003 a 2011

- Trabalhos sobre rádio apresentados nos vários GTs, nos encontros da Compós, de 2000 a 2011

- Trabalhos sobre rádio apresentados nas várias sessões, nos congressos da SBPJor, de 2003 a 2011

- Livros sobre rádio de autores brasileiros

- Produção brasileira de teses e dissertações, de 1987 a 2010

\section{Congressos da Intercom ${ }^{4}$}

A Intercom foi fundada em 1977 e, até 2010, realizou 33 congressos anuais, de âmbito nacional. Os grupos de pesquisa com foco em áreas específicas passaram a funcionar a partir de 1991, os chamados Grupos de Trabalho (GTs). Em 2000, foi feita uma reestruturação dos GTs, com a criação dos Núcleos de Pesquisa. Em 2008, foram criadas as divisões temáticas, "com a finalidade de reunir pesquisadores interessados em temáticas dotadas de legitimação acadêmico-profissional ou que representam objetos demandando elucidação teóricometodológica" 5 . Em 20 anos de atividades, o GP Rádio e Mídia Sonora teve 471 trabalhos apresentados, conforme o quadro a seguir:

\begin{tabular}{|c|c|}
\hline \multicolumn{2}{|c|}{ GP Rádio e Mídia Sonora - Intercom } \\
\hline Ano & $\begin{array}{c}\mathbf{N}^{\mathbf{0}} \text { de trabalhos sobre } \\
\text { rádio }\end{array}$ \\
\hline 1991 & 7 \\
\hline 1992 & 5 \\
\hline 1993 & 6 \\
\hline 1994 & 10 \\
\hline 1995 & 9 \\
\hline 1996 & 13 \\
\hline 1997 & 13 \\
\hline 1998 & 20 \\
\hline 1999 & 24 \\
\hline
\end{tabular}

4 Os dados deste tópico fazem parte do texto: PRATA, Nair. Grupo de Pesquisa Rádio e Mídia Sonora - 20 anos. Trabalho apresentado no GP Rádio e Mídia Sonora, XI Encontro dos Grupos de Pesquisas em Comunicação, evento componente do XXXIV Congresso Brasileiro de Ciências da Comunicação, 2011.

5 Fonte: Normas Regimentais dos Grupos de Pesquisa da Intercom: http://intercom2.tecnologia.ws/images/stories/Normas_Regimentais_dos_Grupos_de_Pesquisas.pdf. Data de acesso: 30/06/2011. 


\begin{tabular}{|l|l|}
\hline 2000 & 13 \\
\hline 2001 & 20 \\
\hline 2002 & 24 \\
\hline 2003 & 38 \\
\hline 2004 & 41 \\
\hline 2005 & 41 \\
\hline 2006 & 29 \\
\hline 2007 & 30 \\
\hline 2008 & 34 \\
\hline 2009 & 44 \\
\hline 2010 & 50 \\
\hline \multicolumn{2}{|c|}{ Total de trabalhos: 471} \\
\hline
\end{tabular}

Nos 20 anos de sessões do GP, 245 pesquisadores diferentes apresentaram trabalhos em equipe ou individualmente. Do total de 245 pesquisadores presentes nestes 20 anos do GP, é importante destacar que apenas 61 deles, ou seja, 25\% participaram com três textos ou mais, número que pode ser considerado pequeno. Em contrapartida, mais da metade, 142 pesquisadores, ou seja, $58 \%$ do total, compareceram com um único texto. A seguir, um quadro com os 33 pesquisadores mais profícuos do grupo, elencados aqui por ordem do número de trabalhos apresentados:

\begin{tabular}{|l|c|}
\hline \multicolumn{1}{|c|}{ Pesquisador } & $\mathbf{N}^{\text {o de trabalhos }}$ \\
\hline Dóris Fagundes Haussen & 17 \\
\hline Mágda Cunha & 15 \\
\hline Nélia Del Bianco & 14 \\
\hline Valci Zuculoto & 13 \\
\hline Nair Prata & 12 \\
\hline $\begin{array}{l}\text { Antonio Adami } \\
\text { Luciano Klöckner } \\
\text { Sônia Virgínia Moreira }\end{array}$ & 10 \\
\hline Luiz Artur Ferraretto & 9 \\
\hline $\begin{array}{l}\text { Álvaro Bufarah Junior } \\
\text { Ana Baumworcel } \\
\text { Marcos Júlio Sergl }\end{array}$ & 8 \\
\hline $\begin{array}{l}\text { Andréa Pinheiro Paiva Cavalcante } \\
\text { Eduardo Meditsch } \\
\text { Mauro José Sá Rego Costa }\end{array}$ & 7 \\
\hline $\begin{array}{l}\text { Júlia Lúcia de Oliveira A. da Silva } \\
\text { Sônia Caldas Pessoa }\end{array}$ & \\
\hline
\end{tabular}

\begin{tabular}{l|l|}
\hline Adriana Ruschel Duval & \\
João Baptista de Abreu & 6 \\
Luiz Maranhão Filho & \\
Moacir Barbosa de Souza & \\
Wanir Campelo & \\
\hline André Barbosa Filho & \\
Antônio Francisco Magnoni & \\
Carmen Lúcia José & \\
Cida Golin & \\
Delma Perdomo Deniz & \\
Gisele Sayeg Nunes Ferreira & \\
Irineu Guerrini Junior & \\
Lia Calabre & \\
Marta Regina Maia & \\
Sandra Sueli Garcia de Sousa & \\
Sergio Francisco Endler & \\
\hline
\end{tabular}

\section{Congressos da Rede Alcar}

A Associação Brasileira de Pesquisadores de História da Mídia (Alcar) realizou oito congressos de âmbito nacional: 2003 (Rio de Janeiro/RJ), 2004 (Florianópolis/SC), 2005 (Novo Hamburgo/RS), 2006 (São Luís/ MA), 2007 (São Paulo/SP), 2008 (Niterói/RJ), 2009 (Fortaleza/CE) e 2011 (Guarapuava/PR). Os trabalhos sobre rádio foram apresentados nas sessões do Grupo de Trabalho História do Rádio.

\begin{tabular}{|c|c|}
\hline \multicolumn{2}{|c|}{ GT História do Rádio - Rede Alcar } \\
\hline Ano & $\mathbf{N}^{\mathbf{0}}$ de trabalhos sobre rádio \\
\hline 2003 & 3 \\
\hline 2004 & 28 \\
\hline 2005 & 31 \\
\hline 2006 & 28 \\
\hline 2007 & 24 \\
\hline 2008 & 36 \\
\hline 2009 & 25 \\
\hline 2011 & 26 \\
\hline \multicolumn{2}{|c|}{ Total de trabalhos: 201} \\
\hline
\end{tabular}

Nos oito congressos, 212 pesquisadores apresentaram suas pesquisas, conforme o quadro a seguir (apresentamos aqui apenas os autores de três textos ou mais): 


\begin{tabular}{|l|c|}
\hline \multicolumn{1}{|c|}{ Pesquisador } & $\begin{array}{c}\text { No de trabalhos } \\
\text { sobre rádio }\end{array}$ \\
\hline $\begin{array}{l}\text { Luciano Klöckner } \\
\text { Nair Prata }\end{array}$ & 7 \\
\hline $\begin{array}{l}\text { Eroltide Honório Silva } \\
\text { João Batista de Abreu } \\
\text { Wanir Campelo }\end{array}$ & 6 \\
\hline Clovis Reis & 5 \\
\hline $\begin{array}{l}\text { Alvaro Bufarah Junior } \\
\text { Ana Baumworcel } \\
\text { Claudia Quadros } \\
\text { Domingo Glenir Santarnecchi }\end{array}$ & \\
\hline $\begin{array}{l}\text { Cida Golin } \\
\text { Edileuson Almeida } \\
\text { Flávia Lúcia Bazan Bespalhok } \\
\text { Graziela Mello Vianna } \\
\text { Ivete Cardoso Roldão } \\
\text { Izani Mustafá } \\
\text { Lia Calabre } \\
\text { Luiz Artur Ferraretto } \\
\text { Marta Regina Maia } \\
\text { Moacir Barbosa de Sousa } \\
\text { Sônia Caldas Pessoa } \\
\text { Vera Lucia Spacil Raddatz }\end{array}$ & \\
\hline
\end{tabular}

\section{Congressos da Compós}

A Associação Nacional dos Programas de PósGraduação em Comunicação (Compós) realizou 20 congressos entre 1992 e 2011. Os anais desses congressos não estão disponíveis no acervo da Compós. A entidade não conta com Grupo de Trabalho (GT) ativo ou inativo específico sobre rádio. No mesmo período, a Compós publicou nove livros com os artigos selecionados pelos próprios participantes dos encontros anuais. Os livros reúnem, em média, dez artigos por ano, entre os mais de cem apresentados no congresso. Em 1993, 1994 e 1995, identificamos dois artigos por ano, que mencionam as palavras rádio, $\mathrm{FM}$, música, horário eleitoral no rádio e na TV, e Associação Brasileira de Rádio e Televisão (ABERT), mas nenhum deles tem o rádio como temática principal.

No período 2000 a 2011, a pesquisa pela palavra-chave rádio foi feita nos anais disponíveis no site da Compós ${ }^{6}$.

6 Os anais da Compós estão disponíveis em www.compos.org.br. A pesquisa contou com a colaboração e a sistematização dos dados no período 2000/2012 da professora Debora Cristina Lopez, da Universidade Federal de Santa Maria (UFSM).

\begin{tabular}{|c|c|}
\hline \multicolumn{2}{|c|}{ Compós } \\
\hline Ano & $\begin{array}{c}\mathbf{N}^{\mathbf{0}} \text { de trabalhos sobre } \\
\text { rádio }\end{array}$ \\
\hline 2000 & 1 \\
\hline 2002 & 2 \\
\hline 2003 & 4 \\
\hline 2005 & 1 \\
\hline 2006 & 1 \\
\hline 2007 & 2 \\
\hline 2008 & 2 \\
\hline 2009 & 2 \\
\hline 2010 & 4 \\
\hline 2011 & 2 \\
\hline \multicolumn{2}{|c|}{ Total de trabalhos: 21} \\
\hline
\end{tabular}

Nos 12 encontros anuais realizados entre 2000 e 2011, 21 pesquisadores apresentaram trabalhos sobre rádio como autor ou em co-autoria.

\begin{tabular}{|c|c|}
\hline Pesquisador & $\begin{array}{c}\mathrm{N}^{\circ} \text { de trabalhos } \\
\text { sobre rádio }\end{array}$ \\
\hline Antonio Adami & \multirow{4}{*}{2} \\
\hline Cicilia M. Krohling Peruzzo & \\
\hline Luiz Artur Ferraretto & \\
\hline Marcelo Kischinhevsky & \\
\hline $\begin{array}{l}\text { Arthur Autran Franco de Sá } \\
\text { Neto }\end{array}$ & \multirow{18}{*}{1} \\
\hline Adilson Vaz Cabral Filho & \\
\hline Andréia Moassab & \\
\hline Cristóvão Domingos de Almeida & \\
\hline Edna Miola & \\
\hline Fernando Kuhn & \\
\hline $\begin{array}{l}\text { Graziela Valadares Gomes de } \\
\text { Mello Vianna }\end{array}$ & \\
\hline João Paulo Malerba & \\
\hline Joel Felipe Guindani & \\
\hline Leandro Ramires Comassetto & \\
\hline Márcia Vidal Nunes & \\
\hline Maria Leandra Bizello & \\
\hline Marcelo Kischinhevsky & \\
\hline Micael Herschmann & \\
\hline Suzy dos Santos & \\
\hline Sérgio Capparelli & \\
\hline Sylvia Regina Bastos Nemer & \\
\hline Valdir Jose Morigi & \\
\hline
\end{tabular}


Os trabalhos sobre rádio são apresentados em GTs distintos já que a entidade não tem um grupo sobre o assunto. O que reúne o maior número de textos sobre o rádio, entre 2000 e 2011 é o GT Economia Política e Políticas de Comunicação, conforme a tabela a seguir:

\begin{tabular}{|c|c|}
\hline GT da Compós & $\begin{array}{l}\mathrm{N}^{\circ} \text { de trabalhos } \\
\text { sobre rádio }\end{array}$ \\
\hline $\begin{array}{l}\text { Economia Política e Políticas de } \\
\text { Comunicação }\end{array}$ & 6 \\
\hline $\begin{array}{l}\text { Políticas e Estratégias de Comu- } \\
\text { nicação }\end{array}$ & \multirow{7}{*}{2} \\
\hline Criação e Poéticas Digitais & \\
\hline Cultura das Mídias & \\
\hline $\begin{array}{l}\text { Estudos de cinema, fotografia e } \\
\text { audiovisual }\end{array}$ & \\
\hline Comunicação e Sociabilidade & \\
\hline $\begin{array}{l}\text { Práticas interacionais e linguagens } \\
\text { na comunicação }\end{array}$ & \\
\hline Comunicação e Política & \\
\hline Mídia e Entretenimento & 1 \\
\hline
\end{tabular}

\section{Congressos da SBPJor ${ }^{7}$}

A Associação Brasileira de Pesquisadores em Jornalismo (SBPJor) foi fundada em 28 de novembro de 2003, durante o I Encontro Nacional de Pesquisadores em Jornalismo, realizado na Universidade de Brasília (UnB). Mais de 100 pesquisadores se reuniram na capital do Brasil para apresentar aproximadamente 60 trabalhos científicos. Nessa data também, os 94 sócios fundadores aprovaram os estatutos da sociedade e elegeram a primeira diretoria. O objetivo da entidade é reunir os pesquisadores de uma determinada área do conhecimento e trabalhar em conjunto com outras associações científicas, acadêmicas e profissionais como Intercom, Compós, Fórum Nacional de Professores de Jornalismo, Federação Nacional de Jornalistas (Fenaj), International Communication Association, International Association for Mass Communication Research, Sociedad Ibero-americana de Periodistas en Internet e ALAIC.

A associação está ligada às agências de fomento como CNPq, Capes, FAPs, governos estaduais e empresas que são parceiras. A entidade reúne atualmente em torno de 300 associados, sendo que 50\% são doutores de mais de 100 instituições brasileiras e de países como Portugal, França e Estados Unidos. Desde a sua funda-

7 As informações deste tópico foram retiradas do site da Associação Brasileira de Pesquisadores em Jornalismo (SBPJor), www.sbpjor.org. br, visitado em 27 de novembro de 2011. ção, a SBPJor realizou nove encontros. Para a pesquisa deste trabalho, foi feito um levantamento dos artigos produzidos e apresentados nos eventos da entidade que tiveram como objeto de pesquisa o rádio, em suas diferentes abordagens. Verificou-se que o tema foi desenvolvido em 44 trabalhos, escritos por 33 pesquisadores de diferentes instituições do Brasil. No quadro a seguir pode-se observar o número de trabalhos apresentados em cada congresso:

\begin{tabular}{|c|c|}
\hline \multicolumn{2}{|c|}{ SBPJor } \\
\hline Ano & $\begin{array}{c}\mathbf{N}^{\mathbf{0}} \text { de trabalhos sobre } \\
\text { rádio }\end{array}$ \\
\hline 2003 & 3 \\
\hline 2004 & 8 \\
\hline 2005 & 3 \\
\hline 2006 & 3 \\
\hline 2007 & 5 \\
\hline 2008 & 6 \\
\hline 2009 & 6 \\
\hline 2010 & 5 \\
\hline 2011 & 5 \\
\hline \multicolumn{2}{|c|}{ Total de trabalhos: 44} \\
\hline
\end{tabular}

Nesses nove encontros, do total de 33 pesquisadores que apresentaram trabalhos sobre o rádio, apenas cinco foram mais frequentes, conforme demonstra levantamento apresentado no quadro a seguir (apresentamos aqui apenas os autores de dois textos ou mais):

\begin{tabular}{|l|c|}
\hline \multicolumn{1}{|c|}{ Pesquisador } & $\begin{array}{c}\text { No de trabalhos } \\
\text { sobre rádio }\end{array}$ \\
\hline Nair Prata & 5 \\
\hline Álvaro Bufarah Junior & 4 \\
\cline { 1 - 1 } $\begin{array}{l}\text { Valci Regina Mousquer Zucu- } \\
\text { loto }\end{array}$ & \multirow{2}{|}{3} \\
\cline { 1 - 1 } Veridiana Pivetta de Mello & \\
\cline { 1 - 1 } Wanir Campelo & \\
\cline { 1 - 1 } Bruna Atti Provenzano & \\
\cline { 1 - 1 } Debora Cristina Lopez & \\
\cline { 1 - 1 } Eduardo Meditsch & \\
\cline { 1 - 1 } Gisele Sayeg Nunes Ferreira & \\
\cline { 1 - 1 } Marcelo Kischinhevsky & \\
\cline { 1 - 1 } $\begin{array}{l}\text { Maria Cláudia Santos } \\
\text { Sônia Caldas Pessoa }\end{array}$ \\
\hline
\end{tabular}




\section{Livros}

Em 2010, o Grupo de Pesquisa Rádio e Mídia Sonora da Intercom se articulou para realizar um levantamento de todos as publicações (livros e artigos) que tivessem o rádio como objeto principal. Num amplo trabalho desenvolvido pelas professoras Débora Cristina Lopez e Izani Mustafá, foram elencadas as principais publicações nacionais e estrangeiras sobre a radiofonia.

A pesquisa realizada neste artigo contempla apenas a produção nacional. Assim, a partir da lista inicial de 2010, traçamos três caminhos: 1. Excluímos os artigos e publicações estrangeiras e de autores estrangeiros; 2. Excluímos as publicações de empresas públicas, privadas ou do terceiro setor, sem um autor definido e 3. Ampliamos a pesquisa, com informações das publicações até 2011. Dessa forma, podemos apontar a existência de pelo menos 208 livros de autores brasileiros, que têm a palavra "rádio" no título ou de forma desdobrada, como radiofonia, radiodifusão, entre outras, ou ainda nomes de programas, de emissoras ou de radialistas:

1. ABDALLA, Clarice. Encontro com a imprensa: 0 rádio lido. Rio de Janeiro, RJ. Forense Universitária Editora.1991.

2. AGUIAR, Ronaldo Conde. Almanaque da Rádio Nacional. Rio de Janeiro: Casa da Palavra, 2007.

3. AGUIAR, Ronaldo Conde. As divas da Rádio $\mathrm{Na-}$ cional. Rio de Janeiro: Casa da Palavra, 2010.

4. ALCIDES, Jota. PRA-8, o Rádio no Brasil. Brasília: Fatorama, 1997.

5. ALMEIDA, Hamilton. Padre Landell de Moura: um herói sem glória. Rio de Janeiro: Record, 2006.

6. ALVES, Lourembergue. O rádio no tempo da radionovela, Cuiabá: EdUFMT, 1999.

7. ANNES, Sérgio R. Radiotransceptores. São Paulo: Fittipaldi, 1995.

8. ARAÚJO, Carlos Brasil de. O escritor, a comunicação e o radiojornalismo. Diretoria de Documentação da Câmara dos Deputados. Brasília, 1972.

9. ASSUMPÇÃO, Zeneida Alves de. Radioescola: uma proposta para o ensino de primeiro grau. São Paulo: Annablume, 1999.

10. ATHAYDES, Andreia. A bistória da radio porto -alegrense contada por quem a fez: Canosas: Ulbra, 2008.

11. AZEVÊDO, Sandra RaqueL dos Santos. Gênero, Rádio \& Educomunicaşão: caminhos entrelaçados. João Pessoa: Editora Universitária, 2005.

12. BACK, Sylvio. Rádio Auriverde (A FEB na Itália). Curitiba: Governo do Estado do Paraná, Secretaria de Estado da Cultura, s/d.
13. BARBEIRO, Heródoto. CBN Mundo Corporativo. São Paulo: Futura, 2006.

14. BARBEIRO, Heródoto; LIMA, Paulo Rodolfo. Manual de radiojornalismo. Rio de Janeiro: Campus, 2001.

15. BARBOSA FILHO, André. Gêneros Radiofônicos: os formatos e os programas em áudio. São Paulo: Paulinas, 2003.

16. BARBOSA FILHO, André; PIOVESAN, Angelo; BENETON, Rosana (org.). Rádio: sintonia do futuro. São Paulo: Paulinas, 2004. (Comunicação-Estudos).

17. BARROS Nelci Moreira de. Do rádio ilustrado à realidade virtual aumentada. Florianópolis: Insular, 2007

18. BAUM, Ana (org.). Vargas, agosto de 54: a história contada pelas ondas do rádio. Rio de Janeiro: Garamond, 2004.

19. BORBA, Mauro. Prezados ouvintes. Porto Alegre: Artes e Ofícios, 1996.

20. BRITO, Paulo. Dás um banho - Roberto Alves, o rádio, o futebol e a cidade. Florianópolis: Editora Insular, $\mathrm{s} / \mathrm{d}$.

21. CABRAL, Sérgio. $A M P B$ na era do rádio. São Paulo: Moderna, 1996.

22. CAFFÉ, M. As cantoras do rádio - 50 anos de som e imagem da MPB. Museu da imagem e do som: São Paulo, 1993.

23. CALABRE, Lia. A Era do Rádio. Rio de janeiro: Jorge Zahar Editor, 2002.

24. CALABRE, Lia. O rádio na sintonia do tempo: radionovelas e cotidiano (1940-1946). Rio de Janeiro: Edições Casa de Rui Barbosa, 2006.

25. CANALITO, Jorge; LEME, Paulinho. Rádio FM: Em Fortaleza é outra bistória. Fortaleza: Prêmios Editora, 2007.

26. CARMINATTI JÚNIOR, Florentino. Brasil, meio século de imprensa: a era de ouro do rádio reminiscências da cidade. Florianópolis: Assembléia Legislativa do Estado de Santa Catarina, 1996.

27. CARVALHO, André e MARTINS, Kao. Habla, Señor. Belo Horizonte: Armazém de Idéias, 1992.

28. CARVALHO, André. (coord.) Manual de jornalismo em rádio: Itatiaia 610 AM. Belo Horizonte: Armazém de Idéias Ltda, 1998.

29. CARVALHO, Juliano Mauricio de e MAGNONI, Antonio Francisco. O novo radio. São Paulo: Senac, 2010.

30. CASÉ, Rafael. Programa Casé - O rádio começon aqui. Mauad: Rio de Janeiro, 1995.

31. CÉSAR, Cyro. Como falar no rádio: prática de locução 
AM e FM; dicas e toques. São Paulo: Ibrasa, 1992.

32. CÉSAR, Cyro. Rádio: a mídia da emoção. São Paulo: Summus, 2005.

33. CÉSAR, Cyro. Rádio: inspiração, transpiração e emoção. São Paulo: Ibrasa, 1997.

34. CESARIO, Danilo Vieira et al. Radionovela: a magia do passado encantando o presente. Fortaleza: LCR, 2006.

35. COELHO NETO, Armando. Rádio Comunitária não é Crime: direito de antena: o espectro eletromagnético como um bem difuso. São Paulo: Ícone, 2002.

36. COELHO, Renato, COELHO Nely e RIBEIRO, Adriana. Caderno de scripts da rádio MEC. Rio de Janeiro: Soarmec, s/d.

37. COGO, Denise Maria. No ar... uma rádio comunitária. Coleção: Comunicação e Estudos, São Paulo: Paulinas, 1998.

38. COMASSETTO, Leandro Ramires. A voz da aldeia - o rádio local e o comportamento da informacão na nova ordem global. Florianópolis: Insular, 2007.

39. COMEGNO Valdir. Nas ondas da magia do Rádio. ABR Editora, 2011.

40. CORAZZA, Helena. Comunicação e relações de gênero em práticas radiofônicas. São Paulo: Paulinas, 2000.

41. CORRÊA, Eli. Segunda Pesquisa de audiência e avaliação do programa radiofónico - Atualidades agricolas. São Paulo: Secretaria de Agricultura do Estado de São Paulo, 1975.

42. COSTA, Eduardo e MARTINS, Kao. Uma paixão chamada Itatiaia. Belo Horizonte: Tamoios, 2010.

43. COSTA, João Ribas da. Educação Fundamental pelo rádio. São Paulo: Imprimatur, 1956.

44. COSTA, Maria Tereza P. da. O Programa Gil Gomes: a justiça em ondas médias. Campinas: Editora Unicamp, 1992.

45. DEL BIANCO, Nélia R.; MOREIRA, Sônia Virgínia (org.). Rádio no Brasil: tendências e perspectivas. Rio de Janeiro/ Brasília: Editora da UERJ/ Editora UnB, 1999.

46. DENARDI, Carol; MEDEIROS, Ricardo. CBN Diário: uma luz no apagão. Editora: Insular, 2007.

47. DILLEMBURG, Sérgio Roberto. Os anos dourados do rádio em Porto Alegre. Porto Alegre: Corag/ARI, 1990.

48. DOMINGUES, Heron. Rádio Nacional - 20 anos de liderança a serviço do Brasil. Rio de Janeiro: Rádio Nacional, 1956.

49. DUMMAR FILHO, João. João Dummar: um pioneiro do rádio. Fortaleza: Edições Demócrito Rocha, 2004.
50. ESPINHEIRA, Ariosto. Rádio e Educação. São Paulo: Melhoramentos, 1934.

51. ESTRELLA, MARIA. Rádio Fluminense FM. Rio de Janeiro: Editora Outras Letras, 2009.

52. FAOUR, Rodrigo. Revista do Rádio: cultura, fuxicos e moral nos anos dourados. Rio de Janeiro: Relume-Dumará: Prefeitura da Cidade do Rio de Janeiro, 2002.

53. FARIA, Álvaro Alves de. Jovem Pan, 50 anos. São Paulo: Maltese, 1994.

54. FARIA, Álvaro Alves de. Jovem Pan-Sat, ano 2000. São Paulo: Maltese, 1997.

55. FÁVERI, Marlene de; LUNA, Gloria Alejandra Guarnizo. Irene de Souza Boemer: Dama do rádio, cronista da cidade. Itajaí: Editora Maria do Cais, 2008.

56. FEDERICO, Maria Elvira Bonavita. História da comunicação: rádio e TV no Brasil. Petrópolis: Vozes, 1982.

57. FELICE, Mauro de. Jornalismo de rádio. Brasilia: Thesaurus Editora, 1981.

58. FERRARETTTO, Luiz Artur. (Org.) ; Klockner, Luciano (Org.) . E o rádio? Novos horizontes midiáticos. Porto Alegre: Editora da PUCRS, 2010. v. 1.

59. FERRARETTO, Luiz Artur. Rádio - O veículo, a história e a técnica. 3. ed. Porto Alegre: Doravante, 2007.

60. FERRARETTO, Luiz Artur. Rádio e capitalismo no Rio Grande do Sul: as emissoras comerciais e suas estratégias de programação na segunda metade do século 20. Canoas: Editora da Ulbra, 2007.

61. FERRARETTO, Luiz Artur. . Rádio no Rio Grande do Sul (anos 20, 30 e 40): dos pioneiros às emissoras comerciais. Canoas: Editora da Ulbra, 2002. 258 p.

62. FERRARETTO, Luiz Artur. ; KOPPLIN, E. . Técnicas de redação radiofônica. Porto Alegre: Sagra-Luzzatto, 1992.

63. FERREIRA, Daniela Carvalho Monteiro e PAIVA, José Eduardo Ribeiro de. O áudio na internet: uma orientação aos profissionais de comunicação e de tecnologia. Uberlância: Edibrás, 2008.

64. FERREIRA, Paulo Cesar. Pilares via satélite: da Rádio Nacional à Rede Globo. Rio de Janeiro: Rocco, 1998.

65. FESTA, Regina (Org.); SILVA, Carlos Eduardo Lins da (Org.). Comunicação popular e alternativa no Brasil. São Paulo: Paulinas, 1986.

66. FLORES, Moacyr. A Radiodifusão no Rio Grande do Sul. Porto Alegre: Plátano, 1997.

67. FOGOLARI: Elide Maria. Laboratório de Rádio: a arte de falar e ouvir. São Paulo: Sepac/ Paulinas.

68. FORNARI, Ernani. O "Incrivel" Padre Landell de 
Moura: o brasileiro precursor das telecomunicações. $2^{\mathrm{a}}$ ed. Rio de Janeiro: Biblioteca do Exército, 1984.

69. FRIDERICHS, Bibiana de Paula. Comunicação popular no rádio comercial. Passo Fundo: UFP, 2002.

70. GALVANI, Walter. Um século de poder: os bastidores da Caldas Júnior. Porto Alegre: Mercado Aberto, 1994.

71. GIRARDI, Ilza; JACOBUS, Rodrigo (orgs). Para fazer Rádio Comunitária com "C" maiúsculo. Porto Alegre: Revolução de Ideias, 2009.

72. GOLDFEDER, Miriam. Por trás das ondas da Rádio Nacional. Rio de Janeiro: Paz e Terra, 1980.

73. GOLIN, Cida; ABREU, João Batista. (Org.). Batalha Sonora: o rádio e a Segunda Guerra Mundial. Porto Alegre: Edipucrs, 2006.

74. GOMES, Ana Luisa Zamboni. Tecendo redes no campo: a comunicaça como ferramenta de desenvolvimento local. Brasília: Núcleo de Estudos Agrários (NEAD), 2003.

75. GOMES, Ana Luisa Zaniboni. Na boca do rádio: o radialista e as políticas públicas. São Paulo: Aderaldo \& Rothschild: Oboré, 2007.

76. GRAÇA, MARCIO. Rádio e TV. São Paulo: Editora LCTE, 2006.

77. GRAMÁTICO, Dáurea. Histórias de gente do rádio. São Paulo: Ibrasa, 2002.

78. GRINBERG, Máximo Simpson (org.). A comunicação alternativa na América Latina. Petrópolis: Vozes, 1987.

79. GRISA, Jairo Angelo. Histórias de Owvinte. Itajaí: Univali, 2003.

80. GUARINOS, Virginia. Manual de narrativa radiofônica. Madrid: Editorial Sintesis, 2009.

81. GUERRA, Márcio. Você, ouvinte, é a nossa meta A importância do rádio no imaginário do torcedor de futebol. Juiz de Fora: Editora Etc, 2000.

82. GURGEL, Amaral. Segredos do rádio teatro. Rio de Janeiro: Bruguera, s.d.

83. HAESER, Lúcio. Continental: A Rádio Rebelde de Roberto Marinho. Florianópolis: Insular, 2007.

84. HARTMANN, Jorge e MUELLER, Nelson (org.). A comunicação pelo microfone. Petrópolis, RJ: Vozes, 1998.

85. HAUSSEN, Dóris Fagundes. Rádio e política: tempos de Vargas e Perón. Porto Alegre: EDPUCRS, 2001. 86. HAUSSEN, Doris; CUNHA, Magda (org.). Rádio brasileiro: episódios e personagens. Porto Alegre: Editora da PUCRS, 2003. (Comunicação, 29).

87. HERD, Érika Franziska. $O$ amigo da madrugada: 0 fenômeno Adelzon Alves. Rio de Janeiro: Vozes/SEEC,
1978.

88. JAMBEIRO, Othon (et alli). Tempos de Vargas: 0 rádio e o controle da informação. Salvador: UFBA, 2004.

89. JORGE, Eliana Lobo de Andrade. Rádio: Show da Manhã e Zé Bettio. São Paulo: Idart, 1980.

90. JUNG, Milton. Jornalismo de Rádio. São Paulo: Contexto, 2004.

91. KAPLAN, S. (Org.). O radiojornalismo renovado. Petrópolis: Vozes, 1994.

92. KISCHINHEVSKY, Marcelo. O rádio sem onda: convergência digital e novos desafios na radiodifusão. Rio de Janeiro: e-Papers, 2007.

93. KLÖCKNER, Luciano (Org.); ENDLER, Sérgio Francisco (Org.). Rádio Ativo - O passado, o presente e o futuro do rádio. Porto Alegre: Evangraf, 2005.

94. KLÖCKNER, Luciano (Org.); PRATA, N. (Org.). História da Mídia Sonora: experiências, memórias e afetos de Norte a Sul do Brasil. Porto Alegre: Edipucrs, 2009.

95. KLÖCKNER, Luciano (Org.); PRATA, N. (Org.). Mídia Sonora em 4 dimensões (ouvintes e falantes; memória e política; programas de rádio; tecnologia e futuro). 1a. ed. Porto Alegre: Editora da PUCRS - EDIPUCRS, 2011.

96. KLÖCKNER, Luciano. A notícia na Rádio Gaúcha - orientações básicas sobre texto, reportagem e produção. 1a.. ed. Porto Alegre/RS: Editora Sulina, 1997.

97. KLÖCKNER, Luciano. Nova Retórica e Rádio Informativo: estudo das programações das emissoras TSF - Portugal e CBN - São Paulo. 1a. ed. Porto Alegre: Editora Evangraf, 2011.

98. KLÖCKNER, Luciano. O Repórter Esso: a sintese radiofônica mundial que fez história - $2^{\mathrm{a}}$ Edição Comemorativa dos 70 anos. $2^{a}$. ed. Porto Alegre: Editora da PUCRS - EDIPUCRS e Editora AGE, 2011.

99. KLOCKNER, Luciano. A notícia na Rádio Gaúcha: orientações básicas sobre texto, reportagem e producão. Porto Alegre: Sulina, 1997.

100. KLÖCKNER, Luciano. O Repórter Esso. A sintese radiofônica que fez história. Porto Alegre: AGE e Edipucrs, 2008.

101. LAGO, Benjamim do. Radiodifusão \& Desenvolvimento. Rio de Janeiro: Livraria Cultural da Guanabara, 1969.

102. LEAL, Sayonara. Rádios comunitárias no Brasil e na França: democracia e esfera pública. Aracaju: Editora UFS, 2008.

103. LENHARO, Alcir. Cantores do Rádio - A trajetória de Nora Ney e Jorge Goulart e o meio artístico de seu tempo. 
Campinas, SP: Editora da Unicamp, 1995.

104. LIMA, Zita de Andrade. Princípios e Técnica de Radiojornalismo: Comunicações e Problemas. Brasília: (ICIFORM), 1970.

105. LIMAVERDE, Narcélio. Senhoras e senhores...História do Rádio e da TV nos anos 50. Fortaleza: Editora Vértice, s/d

106. LOPES, Marciano. Coisas que o tempo levou. A Era do Rádio no Ceará. Fortaleza: Gráfica VT, 1994.

107. LOPES, Maria Immacolata Vassalo. O rádio dos pobres: comunicação de massa, ideologia e marginalidade social. São Paulo: Loyola, 1988.

108. LOPES, Saint-Clair da Cunha. Fundamentos jurídico-sociais da radiodifusão. Rio de Janeiro: Editora Nacional, 1957.

109. LOPES, Saint-Clair da Cunha. Radiodifusão - meio século a serviço da integração nacional. Rio de Janeiro: ABERT, 1973.

110. LOPES, Saint-Clair da Cunha. Radiodifusão hoje. Rio de Janeiro: Temário, 1970.

111.LOPES, Vera Maria de Oliveira Nusdeo. O direito à informação e as concessões de rádio e televisão. São Paulo: Revista dos tribunais, 1997.

112. LÓPEZ VIGIL, José Ignacio. Manual urgente para radialistas apaixonados. São Paulo: Paulinas, 2003.

113.LOPEZ, Débora Cristina. Radiojornalismo hipermidiático: tendências e perspectivas do jornalismo de rádio all news brasileiro em um contexto de convergência tecnológica. Corvilhã: UBI, LabCom Books 2010.

114.LUZ, Dioclécio. $A$ arte de pensar e fazer rádios comunitárias. Brasilia: Fundação Heinrich Böll, 2007.

115.LUZ, Dioclécio. Trilha apaixonada e bem humorada do que é e de como fazerer rádios comunitárias, na intenção de mudar o mundo. Brasília: Ind., 2a ed., 2004.

116. MACHADO, Arlindo e outros. Rádios livres - a reforma agrária no ar. São Paulo: Brasiliense, 1986.

117. MAGDALENA, Jose Carlos. Um rádio no porão. Editora São Paulo: Letras Jurídicas, 2005.

118. MANSUR, Fernando. No ar, o sucesso da Cidade: a que pegon todo mundo de surpresa. Rio de Janeiro: JB, 1984.

119. MARANHÃO FILHO, Luiz. Memória do rádio. Recife: Editorial Jangada, 1991.

120. MARANHÃO FILHO, Luiz. Rádio em todas as ondas. Recife: Ed. Universitária da UFPE, 1998.

121. MARTINS, Fábio. Senhores ouvintes, no ar... a cidade e o rádio. Belo Horizonte: Arte, 1999.

122. MATTOS, David José Lessa (org.). Pioneiros do rádio e da TV no Brasil. São Paulo: Códez, 2004.

123. MEDEIROS, Ricardo. Dramas no Rádio: a radio- novela em Florianópolis nas décadas de 50 e 60. Florianópolis: Insular, 1998.

124. MEDEIROS, Ricardo. O que é radioteatro. Florianópolis/Acaert: Insular, 2008.

125. MEDEIROS, Ricardo; VIEIRA, Lúcia Helena. História do rádio em Santa Catarina. Florianópolis: Insular, 1999.

126. MEDITSCH, E. O Rádio na Era da Informação Teoria e técnica do Novo Radiojornalismo. Florianópolis: Insular, 2001.

127. MEDITSCH, E. Teorias do Rádio - Textos e Contextos. Florianópolis: Insular, 2005.

128. MEDITSCH, E. ZUCULOTO, V. Teorias do Rádio - Textos e Contextos. Florianópolis: Insular, Volume II, 2008.

129. MEDITSCH, Eduardo (org.). Rádio e Pânico. A Guerra dos Mundos, 60 anos depois. Florianópolis: Insular, 1998.

130. MEDITSCH, Eduardo (Org.). Rádio: Sete textos sobre o meio que completou 80 anos de Brasil. 1. ed. Florianópolis: Insular/Posjor-UFSC, 2004.

131. MELLO, Luiz Antonio. A onda maldita: como nasceu a Fluminense FM. Niterói: Xamã, 1999.

132. MELLO, Maria Inês. O fenômeno Zambiasi: o comunicador das massas. Porto Alegre: Martins Livreiro, 1987.

133. MENDONÇA, M. Nas ondas do rádio. Boletim Informativo da Casa Romário Martins. Curitiba: Fundação Cultural de Curitiba, 1996.

134. MICK, Walter. Rádio Digital: a inspirada ferramenta para falar ao cidadão do mundo - Um guia para o profissional do século XXI. Curitiba: Copygraf, 1998.

135. MOREIRA, S. V. BIANCO, Nélia R. Del. O Rádio no Brasil: Tendências e perspectivas. Rio de Janeiro: Rio Fundo, 1991.

136. MOREIRA, Sonia V. Rádio Palanque. Rio de Janeiro: Mil Palavras, 1998.

137. MOREIRA, Sônia Virgínia (Org.). 70 anos de radiojornalismo no Brasil 1941-2011. Rio de Janeiro, UERJ, 2011.

138. MOREIRA, Sonia Virgínia e BIANCO, Nélia R. (org.). Desafios do rádio no século XXI. São Paulo: INTERCOM; Rio de Janeiro: UERJ, 2001.

139. MOREIRA, Sônia Virgínia e LOUZADA, Maria das Graças. Chamada à Ação: manual do radialista que cobre educação. Brasília: Projeto Nordeste/MEC, 1997.

140. MOREIRA, Sonia Virgínia. Rádio em transição: tecnologias e leis nos Estados Unidos e no Brasil. Rio de Janeiro: Mil Palavras, 2002. 
141. MOREIRA, Tânia. Osvaldo Faria - Polêmico e Corajoso. Belo Horizonte: Imprensa Oficial de Minas Gerais, 2001.

142. MURCE, Renato. Bastidores do rádio: fragmentos do rádio ontem e hoje. Rio de Janeiro: Imago Editora Ltda, 1976.

143. MUSTAFÁ, Izani. Alô, alô, Joinville! Está no ar a Rádio Difusora! A radiodifusão em Joinville/SC (19411961). Joinville: Casamarca Ecodesign, 2009.

144. NEUBERGER, Lotário (org.). Radiodifusão no Rio Grande do Sul. Porto Alegre: Plátano, 1997.

145. NUNES, Mônica Rebecca Ferrari. O mito no rádio. A voz e os signos de renovaşão periódica. São Paulo: Annablume, 1993.

146. OLIVEIRA, Catarina Tereza Farias de. Escuta Sonora: Recepção e Cultura Popular nas Ondas das Rádios Comunitárias. Rio de Janeiro, E-papers, 2007

147. ORSINI, Elizabeth. Nas ondas do radio. Rio de Janeiro: Record, 2005.

148. ORTRIWANO, Gisela Swetlana. A informação no rádio: os grupos de poder e a determinação dos conteúdos. São Paulo: Summus, 1985.

149. PARADA, Marcelo. Rádio: 24 horas de jornalismo. São Paulo: Panda, 2000.

150. PERDIGÃO, Paulo. No ar: PRK-30! O mais famoso programa de humor da era do rádio. Editora: Casa da Palavra, 2003.

151. PEREIRA, João Baptista Borges. Cor, profissão e mobilidade - o negro e o rádio em São Paulo. São Paulo: Livraria Pioneira, 1967.

152. PEROSA, Lilian Maria F, de Lima. A hora do clique: análise do programa de rádio Voz do Brasil da Velha à Nova República. São Paulo: Annablume: ECA-USP, 1995.

153. PIMENTEL, Fábio Prado. O rádio educativo brasileiro: uma visão histórica. Rio de Janeiro: Soarmec, 1999. 154. PINHEIRO, Cláudia. A Rádio Nacional. Rio de Janeiro: Nova Fronteira, 2005.

155. PINTO, Luciana Moraes Raso Sardinha. A radiodifusão no direito brasileiro. Belo Horizonte: Del Rey, 1992.

156. PORCHAT, Maria Elisa. Manual de radiojornalismo: Jovem Pan. São Paulo: Ática, 1993.

157. PRADO, Magaly. Produção de Rádio: um manual prático. Rio de Janeiro: Elsevier, 2006.

158. PRATA, Nair (Org). O Rádio entre as montanhas - histórias, teorias e afetos da radiofonia mineira. Belo Horizonte: Editora Fundac, 2010.

159. PRATA, Nair. Panorama do rádio no Brasil - V 1. Florianópolis: Insular, 2011.
160. PRATA, Nair. WEBradio: novos gêneros, novas formas de interação. Florianópolis: Insular, 2009.

161. QUEIROZ, Nelson de Araújo. O rádio em extensão rural. Brasília: Emater, 1985.

162. REIS, Clóvis. Propaganda no rádio: Os formatos de anúncio. Blumenau: Edifurb, 2008.

163. REIS, Rose. Nas ondas do rádio: Identidade e Inclusão dos Nordestinos em São Paulo. São Paulo: Cia dos Livros, 2011.

164. REIS, Sérgio. Making off: histórias bem-humoradas dos primeiros anos do rádio e da TV. Porto Alegre: Artes e Ofícios, 1995.

165. REZENDE, S.; KAPLAN, S. (Orgs.). Jornalismo eletrônico ao vivo. Petrópolis: Vozes, 1995.

166. ROCHA, Amara. Nas ondas da modernização: o rádio e a TV no Brasil de 1950 a 1970. Rio de Janeiro: Aeroplano/Faperj, 2007.

167. ROCHA, Vera Lúcia. Cronologia do rádio paulistano: anos 20 e 30. São Paulo: Centro Cultural São Paulo/ divisão de pesquisa, 1993.

168. RODRIGUES, Ivan Dorneles. Brasileiro, Gaúcho, um Gênio Diferente: Landell de Moura. Porto Alegre: Corag, 2004.

169. ROLDAO, Ivete Cardoso do Carmo. Nas ondas do radio - da PRC-9 à Educativa. Holambra: Editora Setembro, 2008.

170. ROMAIS, Célio. O que é rádio em ondas curtas. São Paulo: Brasiliense, 1994.

171. RUAS, Claudia Mara Stapani. Rádio comunitária: uma estratégia para o desenvolvimento local. Campo Grande: UCDB, 2004.

172.SALOMÃO, Mozahir. Jornalismo Radiofônico e Vinculação Social. São Paulo: AnnaBlume, 2003.

173. SALVADOR, Roberto. A Era do Radioteatro. Rio de Janeiro: Gramma, 2010.

174. SAMPAIO, Mário Ferraz. História do rádio e da TV no Brasil e no mundo. Rio de Janeiro, Achiamé, 1984.

175. SAMPAIO, Walter. Jornalismo Audiovisual: rádio, TV e cinema. Petrópolis, RJ: Vozes, 1971.

176. SANTOS, César Augusto Azevedo. Quem inventou o rádio? Passo Fundo: Clio, 2001.

177.SANTOS, Edmilson Divino dos (Org.). Jornalismo em Rádio. Goiânia: Editora Redentorista, 1993.

178.SANZ, Luiz Alberto Barreto Leite. Dramaturgia da informação radiofônica. Rio de Janeiro: Editora Gama Filho, 1999.

179. SAROLDI, L.C; MOREIRA, S.V. Rádio Nacional - O Brasil em Sintonia. Rio de Janeiro: Jorge Zahar Editor, 2005. 
180. SCHINNER, Carlos Fernando. Manual dos locutore esportivos: como narrar futebol e outros esportes no rádio e na televisão. São Paulo: Panda Books, 2004.

181.SCHIRMER, Lauro. RBS: da voz-do-poste à multimidia. Porto Alegre: L\&PM, 2002.

182.SEVERO, Antunes; GOMES, Marco Aurélio. Memória da Radiodifusão Catarinense. Florianópolis: Insular, 2009.

183.SEVERO, Antunes; MEDEIROS, Ricardo. Caros Ouvintes - Os 60 anos do Rádio em Florianópolis. Florianópolis: Insular, 2005.

184. SILVA, Júlia Lúcia de Oliveira Albano da Silva. Rádio: oralidade mediatizada: o Spot e os elementos da linguagem radiofônica. São Paulo: Annablume, 1999.

185. SILVA, Maurício F. Quem me elegeu foi o rádio. São Paulo: Olho D’ água. 2000.

186. SILVEIRA, Norberto da. Reportagem da legalidade 1961-1991. Porto Alegre: NS Assessoria de Comunicação, 1991.

187. SILVEIRA, Paulo Fernando. Rádios comunitárias. Belo Horizonte: Del Rey, 2001.

188. SOARES, Edileuza. A bola no ar, o rádio esportivo em São Paulo. São Paulo: Summus, 1994.

189. SOLANO, Fernando. Rádio toda hora, em todo lugar. Belo Horizonte: Melhoramentos, 2008.

190. SOUTO, Alceu Salvi. Uma Rádio de Muitas Vidas:

Rádio Viva: Uma história de 50 anos. Bento Gonçalves:

Rede Serrana de Comunicações, 1997.

191.SOUZA, Cláudio Mello e. Impressões do Brasil: a imprensa através dos tempos - rádio, jornal, TV. Rio de Janeiro: Grupo Machine, 1986.

192.SPERBER, George Bernard. Introdução à Peça Radiofônica. São Paulo: Editora Pedagógica e Universitária, 1980.

193. SPRITZER, Mirna. O corpo tornado voz: a experiência pedagógica da peça radiofônica. Porto Alegre: UFRGS, 2005.

194.SPRITZER, Mirna; GRABAUSKA, Raquel. Bem lembrado: histórias do radioteatro em Porto Alegre. Porto Alegre: AGE, 2002.

195. TADEU, AGUINALDO. O dono do rádio. Editora Rio de Janeiro: Giostri, 2011.

196.TAVARES, Mariza; FARIA, Giovanni (orgs). $C B N$, a rádio que toca notícia: a bistória da rede e as principais coberturas, estilo e linguagem do all news, jornalismo político, econômico e esportivo, a construção da marca, o modelo de negócios. Rio de Janeiro: Editora Senac Rio, 2006.

197. TAVARES, Reynaldo C. Histórias que o rádio não contou: do galena ao digital, desvendando a radiodifusão no Brasil e no mundo. São Paulo: Negócio, 1997.
198. TAVES, Rodrigo. Paixao pelo rádio. São Paulo: Maquinaria Editora, 2009.

199. THOMÉ, Luís Touguinha et al. Na onda do progresso: o papel do rádio no desenvolvimento do Rio Grande do Sul. Porto Alegre: Alternativa Consultoria, 2001. $144 \mathrm{p}$.

200. TINHORÃO, José Ramos. Música Popular, do gramofone ao rádio e TV. São Paulo: Ática, 1981.

201. VAMPRÉ, Octávio Augusto. Raízes e evolução do rádio e da televisão. Porto Alegre: Feplam, 1979.

202. VIEIRA, Jonas. César de Alencar, a voz que abalou o rádio. Rio de Janeiro: Valda, 1993.

203. VIOLA, Denise; GUILHON, Madalena; PERNA, Mara Regia di; LADEIRA, Taís; CORRAL, Thais e AFFONSO, Renata. Fažendo gênero no rádio. Rio de Janeiro: Cemina, 1998.

204. WAINBERG, Jacques Alkalai. Império das palavras: estudo comparado dos Diários e Emissoras Associados, de Assis Chateaubriand, e Hearst Corporation, de William Randolph Hearst. Porto Alegre: Editora da PUCRS, 1997. 314p.

205. WITIUK, Luiz. O som das ruas: um estudo sobre o radiojornalismo curitibano. Curitiba: Pós-Escrito: Instituto Cultural de Jornalistas do Paraná, 2008.

206.XAVIER, Antônio Carlos dos Santos. A linguagem do rádio. Catanduva: Respel, 2005.

207.ZAREMBA, Lílian. Entreouvidos: sobre Rádio e Arte. Rio de Janeiro, Soamerc-Oi Futuro, 2009.

208.ZAREMBA, Lílian; BENTES, Ivana (org.). Rádio Nova, constelações da radiofonia contemporânea (v. 1,2,3). Rio de Janeiro, Edição Publique-Laboratório de Editoração da Escola de Comunicação da Universidade Federal do Rio de Janeiro, 1997, 1999, 2000.

Como o propósito desta pesquisa é identificar os teóricos e pesquisadores brasileiros mais produtivos e influentes sobre o tema rádio, a partir da lista dos livros realizamos um levantamento sobre os autores com maior número de publicações. Desconsideramos os autores com apenas um livro publicado e relacionamos abaixo, em ordem decrescente, os pesquisadores com dois livros ou mais. É importante destacar que relacionamos o autor de forma isolada, não levando em conta se o livro foi publicado individualmente ou se em forma de organização com outros pesquisadores: 


\begin{tabular}{|c|c|}
\hline Autor & $\begin{array}{c}\mathbf{N}^{\mathbf{o}} \text { de livros } \\
\text { publicados sobre } \\
\text { rádio }\end{array}$ \\
\hline Luciano Klöckner & \multirow{2}{*}{8} \\
\hline Sonia Virginia Moreira & \\
\hline Eduardo Meditsch & \multirow{5}{*}{5} \\
\hline Luiz Artur Ferraretto & \\
\hline Nair Prata & \\
\hline Nélia R Del Bianco & \\
\hline Ricardo Medeiros & \\
\hline Cyro César & \multirow[t]{2}{*}{3} \\
\hline Saint-Clair da Cunha Lopes & \\
\hline Álvaro Alves de Faria & \multirow{15}{*}{2} \\
\hline Ana Luisa Zamboni Gomes & \\
\hline André Barbosa Filho & \\
\hline André Carvalho & \\
\hline Antunes Severo & \\
\hline Dioclécio Luz & \\
\hline Dóris Fagundes Haussen & \\
\hline Heródoto Barbeiro & \\
\hline Kao Martins & \\
\hline Lia Calabre & \\
\hline Lílian Zaremba & \\
\hline Luiz Maranhão Filho & \\
\hline Mirna Spritzer & \\
\hline Ronaldo Conde Aguiar & \\
\hline Sydney Kaplan & \\
\hline
\end{tabular}

\section{A produção brasileira de teses e dissertações (1987-2010)}

A produção brasileira de teses e dissertações é muito recente porque os cursos de pós-graduação no Brasil, em relação a países da Europa e Estados Unidos, surgiram há quatro décadas. A Escola de Comunicação e Artes de São Paulo (ECA-USP) iniciou suas atividades em março de 1967, mas somente criou o primeiro mestrado em Ciências da Comunicação do Brasil em 8 de janeiro de 1972 e a primeira turma de doutorado em Ciências da Comunicação em $1^{\circ}$ de agosto de 1980. A ECA -USP foi a primeira universidade no Brasil a oferecer o ciclo completo para formação acadêmica de graduação, mestrado e doutorado.

A fim de quantificar e analisar qualitativamente as teses e dissertações produzidas nos últimos 40 anos, organizamos um inventário a partir das pesquisas científicas publicadas no Portal Capes, no período de 1987 a 2010, cujo tema envolva o rádio. A busca utilizou como palavras-chave "rádio", "radiojornalismo" e "história do rádio" e considerou os trabalhos produzidos em todas as áreas de conhecimento elencadas no site. Entre elas, além da Comunicação, também Educação, História, Sociologia e Direito. Também foram considerados os trabalhos que tivessem fundamentação teórica embasada em autores das áreas de Comunicação e História. Ao longo destes 23 anos foram publicadas um total de 125 teses sobre o rádio. Apenas nos anos de 1988, 1989, 1991, 1993, 1994 e 1997 não foram localizadas ocorrências em pesquisa de doutorado que tratasse sobre rádio.

Observando cada ano, verificamos que os de 2004 e 2005 foram os que tiveram maior produção. Em cada ano foram defendidas 14 pesquisas. Em 2008, foram apresentadas 13 teses, em 2002 e 2010, 12 teses em cada ano, e em 2006, 11 teses.

\begin{tabular}{|c|c|}
\hline Ano & 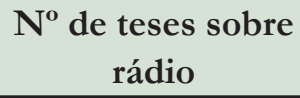 \\
\hline 1987 & 1 \\
\hline 1988 & 0 \\
\hline 1989 & 0 \\
\hline 1990 & 2 \\
\hline 1991 & 0 \\
\hline 1992 & 3 \\
\hline 1993 & 0 \\
\hline 1994 & 0 \\
\hline 1995 & 1 \\
\hline 1996 & 3 \\
\hline 1997 & 0 \\
\hline 1998 & 4 \\
\hline 1999 & 3 \\
\hline 2000 & 4 \\
\hline 2001 & 6 \\
\hline 2002 & 12 \\
\hline 2003 & 7 \\
\hline 2004 & 14 \\
\hline 2005 & 14 \\
\hline 2006 & 11 \\
\hline 2007 & 5 \\
\hline 2008 & 13 \\
\hline 2009 & 10 \\
\hline 2010 & 12 \\
\hline $\begin{array}{c}\text { Total de teses sobre rá- } \\
\text { dio: } 125\end{array}$ & \\
\hline
\end{tabular}

Ao listar o número de teses em cada um dos 26 
estados e mais o Distrito Federal, verificamos que em São Paulo, entre 1987 e 2010, foram defendidas 66 teses. Deste total, 63 foram pesquisas realizadas em diferentes universidades e faculdades da capital São Paulo. Bem atrás está o Rio Grande do Sul, com 16 teses, sendo que 13 foram apresentadas em Porto Alegre, capital, onde funcionam a Universidade Federal do Rio Grande do Sul e a Pontifícia Universidade Católica do Rio Grande do Sul, e 3 em São Leopoldo, onde está instalada a Universidade do Vale do Rio dos Sinos. Em terceiro lugar está o Rio de Janeiro, com 16 pesquisas, sendo 12 da cidade do Rio de Janeiro e duas de Niterói.

\begin{tabular}{|l|c|}
\hline \multicolumn{1}{|c|}{ Cidades } & $\begin{array}{c}\text { No de teses sobre } \\
\text { rádio }\end{array}$ \\
\cline { 1 - 1 } São Paulo (SP) & 63 \\
\hline Rio de Janeiro (RJ) & 14 \\
\hline Porto Alegre (RS) & 13 \\
\cline { 1 - 1 } Brasília (DF) & \multirow{2}{*}{5} \\
\cline { 1 - 1 } Fortaleza (CE) & \multirow{2}{*}{3} \\
\cline { 1 - 1 } Belo Horizonte (MG) & \\
\cline { 1 - 1 } Campinas (SP) & \\
\cline { 1 - 1 } São Leopoldo (RS) & \\
\cline { 1 - 1 } Natal (RN) & \\
\cline { 1 - 1 } Niterói (RJ) & \\
\cline { 1 - 1 } Curitiba (PR) & \\
\cline { 1 - 1 } Florianópolis (PE) & \\
\cline { 1 - 1 } Recife (PE) & \\
\cline { 1 - 1 } Salvador (BA) & \\
\hline
\end{tabular}

O pioneirismo da ECA-USP em ser a primeira universidade brasileira a ofertar os cursos de pós-graduação em Ciências da Comunicação se reflete na terceira análise. As universidades com maior número de teses defendidas são, por ordem, Universidade de São Paulo, com 37 pesquisas; Pontifícia Universidade Católica de São Paulo, com 13; e Universidade Federal do Rio de Janeiro, com 12. É necessário considerar que a primeira universidade brasileira com uma pós-graduação com doutorado em Ciências da Comunicação foi a Escola de Comunicações e Artes da Universidade Federal de São Paulo. (ECA-USP). Em quarto e quinto lugares estão, respectivamente, a Pontifícia Universidade Católica do Rio Grande do Sul, com oito teses defendidas e a Universidade Federal do Rio Grande do Sul, com sete pesquisas.

O segundo programa de pós-graduação a ser fundado no país foi em Comunicação e Cultura da Es- cola de Comunicação da Universidade Federal do Rio de Janeiro, conhecida como ECO-UFRJ. O mestrado começou a funcionar em 1973 e o doutorado em 1983. O terceiro programa de pós-graduação é o da Pontifícia Universidade Católica de São Paulo (PUC-SP), em Comunicação e Semiótica. O mestrado iniciou em 1978 e o doutorado em 1981.

\begin{tabular}{|l|c|}
\hline \multicolumn{1}{|c|}{ Universidade } & $\begin{array}{c}\mathbf{N}^{\text {o }} \text { de teses } \\
\text { sobre rádio }\end{array}$ \\
\hline Universidade de São Paulo & 37 \\
\hline $\begin{array}{l}\text { Pontifícia Universidade Católica de } \\
\text { São Paulo }\end{array}$ & 13 \\
\hline $\begin{array}{l}\text { Universidade Federal do Rio de } \\
\text { Janeiro }\end{array}$ & 12 \\
\hline $\begin{array}{l}\text { Pontifícia Universidade Católica do } \\
\text { Rio Grande do Sul }\end{array}$ & 7 \\
\hline $\begin{array}{l}\text { Universidade Federal do Rio Grande } \\
\text { do Sul }\end{array}$ & 5 \\
\hline Universidade de Brasília & 2 \\
\hline $\begin{array}{l}\text { Universidade do Vale do Rio dos } \\
\text { Sinos }\end{array}$ & 3 \\
\hline Universidade Federal Fluminense & \\
\hline
\end{tabular}

Com relação à análise das teses distribuídas em áreas de conhecimento, verificamos que em primeiro lugar os estudos sobre rádio se concentram em Comunicação. Das 125 pesquisas, 65 foram produzidas nessa área. Em segundo lugar está o curso de História, com 15 teses, em terceiro lugar, a área da Educação, e em quarto lugar, Sociologia. No entanto, percebemos que trabalhos envolvendo o rádio também foram desenvolvidos em outras áreas como Estudos Linguísticos, Direito, Antropologia, Ciências da Religião e Ciência Política.

\begin{tabular}{|l|c|}
\hline \multicolumn{1}{|c|}{ Áreas de conhecimento } & $\begin{array}{c}\mathbf{N}^{\mathbf{o}} \text { de teses so- } \\
\text { bre rádio }\end{array}$ \\
\hline Comunicação & 65 \\
\hline História & 15 \\
\hline Educação & 9 \\
\hline Sociologia & 8 \\
\hline Estudos Linguísticos & 5 \\
\hline Direito & 4 \\
\hline Ciências Sociais & 3 \\
\hline Antropologia & 2 \\
\hline Ciências da Religião & 2 \\
\hline
\end{tabular}




\begin{tabular}{|c|c|}
\hline Ciência Política & \multirow{9}{*}{1} \\
\hline Teatro & \\
\hline Engenharia Elétrica & \\
\hline $\begin{array}{l}\text { Epidemiologia experimental } \\
\text { aplicado às zoonoses }\end{array}$ & \\
\hline Serviço Social & \\
\hline $\begin{array}{l}\text { Direitos Humanos e Desenvolvi- } \\
\text { mento }\end{array}$ & \\
\hline Música & \\
\hline Geografia & \\
\hline Administração & \\
\hline Total de teses: & \\
\hline
\end{tabular}

O Portal Capes também disponibiliza para pesquisas as dissertações publicadas no período de 1987 até 2010. Nesse período, encontramos 486 pesquisas realizadas em nível de mestrado, em todo o país, em diferentes programas de várias universidades. As maiores produções ocorreram nos últimos três anos. Em 2010, 2009 e 2010, respectivamente, foram escritas 46, 44 e 41 pesquisas que tiveram como tema principal o veículo rádio.

Em 2006 e 2000, foram realizadas 35 dissertações, em cada ano. Já em 2007 e 2002, foram registradas, em cada ano, 34 defesas de dissertações. Somente em 2005 foram 31 trabalhos de mestrado. A tabela a seguir mostra também que somente depois de 1993 superaram a marca de dez trabalhos por ano.

\begin{tabular}{|c|c|}
\hline Ano & $\begin{array}{c}\mathbf{N}^{\mathbf{o}} \text { de dissertações sobre } \\
\text { rádio }\end{array}$ \\
\hline 1987 & 1 \\
\hline 1988 & 3 \\
\hline 1989 & 3 \\
\hline 1990 & 3 \\
\hline 1991 & 5 \\
\hline 1992 & 5 \\
\hline 1993 & 11 \\
\hline 1994 & 10 \\
\hline 1995 & 7 \\
\hline 1996 & 6 \\
\hline 1997 & 18 \\
\hline 1998 & 14 \\
\hline 1999 & 26 \\
\hline 2000 & 35 \\
\hline 2001 & 25 \\
\hline 2002 & 34 \\
\hline
\end{tabular}

\begin{tabular}{|c|c|}
\hline 2003 & 25 \\
\hline 2004 & 25 \\
\hline 2005 & 31 \\
\hline 2006 & 35 \\
\hline 2007 & 34 \\
\hline 2008 & 41 \\
\hline 2009 & 44 \\
\hline 2010 & 46 \\
\hline $\begin{array}{c}\text { Total de disser- } \\
\text { tações: } 486\end{array}$ \\
\hline
\end{tabular}

Na tabela a seguir, verificamos que a produção de dissertações, a exemplo das teses, também se concentrou nos estados da região Sudeste e Sul, consequentemente, também, por causa do surgimento dos programas de pós-graduação nas suas capitais e grandes cidades. Em primeiro lugar está São Paulo com 77 pesquisas, sendo que 64 foram defendidas na capital São Paulo e 14 em Campinas. Na segunda posição de produções encontrase o Rio de Janeiro, com 68. Deste total, 47 são pesquisas defendidas na capital Rio de Janeiro e 21 em Niterói. $\mathrm{Na}$ terceira posição está o Rio Grande do Sul, com 45 trabalhos. Destes, 28 foram realizadas em Porto Alegre e 17 em São Leopoldo. Nas posições seguintes localizamos Brasília, com 25 dissertações, Minas Gerais com 17 e Pernambuco com 16.

\begin{tabular}{|c|c|}
\hline Cidades & $\begin{array}{c}\mathbf{N}^{\circ} \text { de dissertações sobre } \\
\text { rádio }\end{array}$ \\
\hline São Paulo (SP) & 64 \\
\hline Rio de Janeiro (RJ) & 47 \\
\hline Porto Alegre (RS) & 28 \\
\hline Brasília (DF) & 25 \\
\hline Niterói (RJ) & 21 \\
\hline Belo Horizonte (MG) & \multirow[t]{2}{*}{17} \\
\hline São Leopoldo (RS) & \\
\hline Recife (PE) & 16 \\
\hline Campinas (SP) & 14 \\
\hline Curitiba (PR) & 13 \\
\hline Florianópolis (SC) & \multirow[t]{2}{*}{11} \\
\hline João Pessoa (PB) & \\
\hline Cuiabá (MT) & \multirow{3}{*}{4} \\
\hline Goiânia (GO) & \\
\hline Natal (RN) & \\
\hline
\end{tabular}




\begin{tabular}{|l|c|}
\hline Belém (PA) & \multirow{2}{*|}{2} \\
\cline { 1 - 1 } Teresina (PI) & \\
\hline Vitória (ES) & \\
\hline Campo Grande (MS) & 1 \\
\hline Rio Branco (AC) & \\
\hline
\end{tabular}

Quando comparamos o número de dissertações produzidas em cada universidade, constatamos que a maior produção está na Universidade de São Paulo, onde está instalada a Escola de Comunicação e Artes (ECA), com 51 trabalhos. Em segundo lugar está a Universidade Federal do Rio de Janeiro (UFRJ), com 29 pesquisas, e em terceiro, a Pontifícia Universidade Católica de São Paulo. $\mathrm{Na}$ tabela a seguir está a sequência de produções nas demais universidades que registraram o maior número de defesas de dissertações, por ordem: Universidade de Brasília, com 22 pesquisas, Universidade Federal Fluminense, com 21, e Universidade do Vale do Rio dos Sinos, com 16. Na Pontifícia Universidade Católica do Rio Grande do Sul e na Universidade Federal do Rio Grande do Sul, foram produzidas, em cada instituição, 13 trabalhos usando como tema o rádio.

\begin{tabular}{|l|c|}
\hline \multicolumn{1}{|c|}{ Universidade } & $\begin{array}{c}\mathbf{N}^{\mathbf{0}} \text { de dissertações } \\
\text { sobre rádio }\end{array}$ \\
\hline Universidade de São Paulo & 51 \\
\hline $\begin{array}{l}\text { Universidade Federal do Rio } \\
\text { de Janeiro }\end{array}$ & 29 \\
\cline { 1 - 2 } $\begin{array}{l}\text { Pontifícia Universidade } \\
\text { Católica de São Paulo }\end{array}$ & 27 \\
\hline Universidade de Brasília & 22 \\
\hline $\begin{array}{l}\text { Universidade Federal Flu- } \\
\text { minense }\end{array}$ & 21 \\
\cline { 1 - 2 } $\begin{array}{l}\text { Universidade do Vale do Rio } \\
\text { dos Sinos }\end{array}$ & 16 \\
\cline { 1 - 2 } $\begin{array}{l}\text { Pontifícia Universidade } \\
\text { Católica do Rio Grande do } \\
\text { Sul }\end{array}$ & 13 \\
\cline { 1 - 2 } $\begin{array}{l}\text { Universidade Federal do Rio } \\
\text { Grande do Sul }\end{array}$ & \\
\hline
\end{tabular}

No mapeamento realizado, também comparamos as dissertações distribuídas em áreas de conhecimento. Do total, 486 dissertações produzidas e publicadas no Portal Capes foram identificadas 230 produções somente na área da Comunicação. Em segundo lugar, a área escolhida para desenvolver as pesquisas cujo tema envolveu o rádio foi Educação e, em terceiro lugar, está
História. Nos demais cursos de pós-graduação, o número de trabalhos não ultrapassa dez, de acordo com os dados da tabela a seguir:

\begin{tabular}{|c|c|}
\hline Áreas de conhecimento & $\begin{array}{c}\mathbf{N}^{\circ} \text { de dissertações } \\
\text { sobre rádio }\end{array}$ \\
\hline Comunicação & 230 \\
\hline Educação & 59 \\
\hline História & 34 \\
\hline Direito & \multirow[t]{2}{*}{9} \\
\hline Ciências Sociais & \\
\hline Ciência Política & \multirow[t]{2}{*}{5} \\
\hline Música & \\
\hline Antropologia & 4 \\
\hline Estudos Linguísticos & \multirow{3}{*}{3} \\
\hline Ciências da Religião & \\
\hline Administração & \\
\hline Serviço Social & 2 \\
\hline Sociologia & 1 \\
\hline
\end{tabular}

Observando as pesquisas de pós-graduação em mestrado e doutorado pelo olhar de gênero, verificamos que a produção realizada por homens e mulheres é muito próxima. As mulheres, no entanto, estão em vantagem. No total de 125 teses, 72 foram produzidas por mulheres, o que corresponde a $57,6 \%$. As demais 53 , por homens, o que corresponde a 42,4\%. Com relação às dissertações, de um total de 486, 260 foram produzidas por mulheres, representando $53,4 \%$, e 226 por homens, representando $46,6 \%$.

\begin{tabular}{|c|c|c|c|}
\hline \multicolumn{2}{|c|}{ Teses } & \multicolumn{2}{c|}{ Dissertações } \\
\hline Homens & Mulheres & Homens & Mulheres \\
\hline 53 & 72 & 226 & 260 \\
\hline \multicolumn{2}{|c|}{ Total de teses: 125} & \multicolumn{2}{c|}{ Total de dissertações: 486 } \\
\hline
\end{tabular}

O mapeamento das teses e dissertações produzidas no Brasil, no período de 1987 a 2010, possibilitou a verificação de algumas curiosidades, como a escrita de pesquisas sobre o rádio em diferentes áreas do conhecimento. Em 1997, Cladecir Alberto Schenkel defendeu o "Estudo de um processo cultural na relação entre "colonos e a Sadia": o caso da Micro-região do Alto Chuguai Catarinense", dissertação realizada no curso de Desenvolvimento, Agricultura e Sociedade da Universidade Federal Rural do Rio de Janeiro, em que a rádio que a 
indústria de alimentos Sadia possui e como a utiliza para veicular seus projetos junto aos colonos, visando a modernização da agropecuária e a ideologia da família Sadia.

Um outro exemplo é a dissertação de David Lindebaum "A Propaganda de Goebbels: Um caminho para a construção da tecnologia do medo", realizada no mestrado de Língua Hebraica Literatura e Cultura Judaica, na Universidade de São Paulo, em 1997. Nesse trabalho, o autor estuda como o Terceiro Reich se apropria do mass midia e da radiodifusão para persuadir as pessoas por meio do medo. No mestrado de Fonoaudiologia, da Pontifícia Universidade Católica de São Paulo, em 2000, Claudia Araújo Navarro defendeu a pesquisa "Perfil Vocal e Análise Acústica da Qualidade Vocal de Locutores Esportivos", que traça um perfil vocal de locutores esportivos do rádio, com relação ao desenvolvimento da voz profissional e aspectos relacionados com a narração esportiva: a postura, a fala, o uso da voz e hábitos vocais; e analisar acusticamente a qualidade de voz utilizada no estilo de locução esportiva.

Isabel Cristina Dias Bertevelli, que fez seu mestrado em Artes, na Universidade Estadual Paulista Júlio de Mesquita Filho, em 2000, reconstitui, no "Elsie Houston (1902 - 1943): cantora e pesquisadora brasileira", a memória histórica e artística de Elsie Houston. A artista que se apresentava em salas de concertos e teatros do Rio de Janeiro, São Paulo e Buenos Aires, também teve, na Rádio NBC de Nova Iorque, um programa semanal de música brasileira. Outro caso é a pesquisa de Wilker Luiz Gadelha Maia, "Um Estudo da Viabilidade de Links de Rádio Freqüência para Integração de Redes de Computadores na UFACNet e Região do Acre", desenvolvida no mestrado de Ciências da Computação, na Universidade Federal de Santa Catarina, em 2000, reconstitui parte da história da comunicação sem fio, a partir do físico italiano Guglielmo Marconi, que utilizou os códigos telegráficos da época, até os dias de hoje com a utilização de redes sem fio entre equipamentos fixos e móveis através de antenas transmissoras e receptoras de dados deixando de lado a cada estrutura de cabeamento.

Para completar os diferentes exemplos, citamos também a dissertação produzida no mestrado de Saúde Publica na Universidade de São Paulo, em 2007, de Marcelus William Janes, "A contribuição da comunicação para a saúde: Estudo de comunicação de risco via rádio na Cidade de São Paulo", em que ele analisa a programação das rádios comunitárias: "8 de Dezembro", situada na Cidade de Vargem Grande Paulista e "Cantareira", situada na Vila Brasilândia, município de São Paulo, e os discursos de seus ouvintes sobre a comunicação de riscos sanitários inerentes ao campo da vigilância sanitária. O autor busca compreender a influência destas mensagens nos hábitos cotidianos desses ouvintes.

\section{Quem é quem na pesquisa em rádio no Brasil}

A partir da pesquisa realizada por este trabalho, podemos identificar os principais teóricos e pesquisadores de rádio do país. Todos eles têm em comum algumas características: são jornalistas com experiência no mercado radiofônico; possuem mestrado e/ou doutorado com pesquisa sobre rádio; participam com grande frequência de congressos e eventos de comunicação com apresentação de investigações que têm o rádio como objeto e a maioria deles - a exceção é apenas o professor Luciano $\mathrm{Klöckner}^{8}$ - esteve ou está à frente da coordenação do Grupo de Pesquisa Rádio e Mídia Sonora da Intercom, uma comprovação inequívoca da importância do GP no cenário da pesquisa radiofônica no país. Apresentamos aqui a lista por ordem alfabética.

Um dos nomes mais atuantes é o da professora da Pontifícia Universidade Católica do Rio Grande do Sul Dóris Fagundes Haussen, que coordenou a implantação do GP Rádio e Mídia Sonora da Intercom, em 1991, no congresso da Intercom realizado na PUC-RS e coordenou o grupo até 1993. Na época, convidou colegas do Sul do país, entre outros, para participarem da seleção de textos e envio de trabalhos. Dóris fez o doutorado em Ciências da Comunicação na Universidade de São Paulo (USP), e produziu a tese "Rádio e política: tempos de Vargas e Perón”, em 1993. Tem pós-doutorado pela Universitad Autónoma de Barcelona e nove livros publicados e/ou organizados (dois exclusivamente sobre rádio, um deles na segunda edição) e também é, atualmente, membro do corpo editorial de cinco revistas científicas: Estudos em Jornalismo e Mídia; Conexão, Comunicação e Cultura; Revista Latinoamericana de Ciencias de La Comunicación; Revista Fronteiras - Estudos Midiáticos e Rastros.

Eduardo Meditsch é uma das maiores lideranças do país quando o assunto é rádio. Coordenou o GP Rádio e Mídia Sonora no período de 2003 a 2004. É pósdoutor pela University of Texas at Austin (2011), doutor em Ciências da Comunicação/Jornalismo pela Universidade Nova de Lisboa (1997) e professor da Universidade Federal de Santa Catarina, onde atua na graduação e pósgraduação em Jornalismo. Integra conselhos editoriais de dezoito revistas acadêmicas do Brasil, América Latina, 8 O professor Luciano, no entanto, coordenou, no período 20102011, o GT História do Rádio da Associação Brasileira de História da Mídia (Alcar). 
Portugal e Espanha, e de duas editoras de livros. Tem nove livros publicados e/ou organizados (cinco sobre rádio), como Teorias do Rádio: textos e contextos (em dois volumes) e O Rádio na Era da Informação: Teoria e Técnica do Novo Radiojornalismo.

Luciano Klöckner é doutor em Comunicação Social pela Pontifícia Universidade Católica do Rio Grande do Sul (2003) e pós-doutor pelo Instituto de Estudos Jornalísticos da Faculdade de Letras da Universidade de Coimbra, em Portugal (2009). É professor adjunto da Faculdade de Comunicação Social (Famecos) da PUC-RS e integra o Conselho Editorial da editora da Universidade e o Conselho Deliberativo da Fundação Piratini. É um dos grandes destaques, no Brasil, sobre história do rádio e sua tese de doutorado sobre o Repórter Esso se tornou uma referência. Tem nove livros publicados (oito sobre rádio), entre eles, o antológico O Repórter Esso: a sintese radiofónica mundial que fez história e ainda Nova Retórica e Rádio Informativo: estudo das programações das emissoras TSF Portugal e CBN. Escreveu 15 capítulos em livros.

Coordenador do GP Rádio e Mídia Sonora por dois mandatos (2007-2010), Luiz Artur Ferraretto também se destaca com uma larga produção voltada para o rádio. Professor da Faculdade de Biblioteconomia e Comunicação da Universidade Federal do Rio Grande do Sul, em Porto Alegre, concluiu o doutorado em 2005, no Programa de Pós-Graduação em Comunicação e Informação da PUC-RS. Tem seis livros publicados (cinco sobre rádio), alguns com várias edições, como Rádio - $O$ veículo, a bistória e a técnica. A produção do professor Ferraretto inclui 22 capítulos publicados em livros e 13 artigos publicados em periódicos.

Mágda Cunha é doutora em Linguística e Letras (2002) pela Pontifícia Universidade Católica do Rio Grande do Sul e é professora titular do curso de Jornalismo, da Famecos/PUC-RS e do Programa de PósGraduação em Comunicação Social da mesma instituição. Coordenou o GP Rádio e Mídia Sonora da Intercom pelo período de dois anos (2005-2006). A pesquisadora, que é diretora da Faculdade de Comunicação Social, da Pontifícia Universidade Católica do Rio Grande do Sul é organizadora, com Dóris Fagundes Haussen, do livro Rádio brasileiro: episódios e personagens. Também tem $12 \mathrm{ca-}$ pítulos publicados em livros e 23 artigos publicados em periódicos.

A atual coordenadora do GP Rádio e Mídia Sonora da Intercom, Nair Prata, também vem se destacando com uma frequente produção sobre rádio, apresentada principalmente em congressos da área de Comunicação. É jornalista, doutora em Linguística Aplicada (UFMG) com pesquisa em radiojornalismo e mídias digitais, professora adjunta do curso de Jornalismo da Universidade Federal de Ouro Preto (UFOP) e diretora administrativa da Associação Brasileira de História da Mídia (Alcar). Tem seis livros publicados (cinco sobre rádio), o mais recente é o Panorama do rádio no Brasil (2011). Tem 11 capítulos publicados em livros.

Nélia Del Bianco é professora adjunta da Faculdade de Comunicação da Universidade de Brasília (UnB), doutora em Comunicação pela ECA-USP (2004) e pósdoutora pela Universidade de Sevilha (2009). Coordenou o GP Rádio e Mídia Sonora da Intercom de 1995 a 1999, tem quatro livros publicados (dois sobre rádio), como Desafios do rádio no século XXI e Rádio no Brasil: tendências e perspectivas, organizados com Sônia Virgínia Moreira. Nélia tem ainda 17 capítulos publicados em livros.

Sônia Virgínia Moreira, professora adjunta do Departamento de Jornalismo e do Programa de PósGraduação em Comunicação da Universidade do Estado do Rio de Janeiro, é doutora em Ciências da Comunicação pela Universidade de São Paulo (1999). É, entre os pesquisadores brasileiros, uma das que tem maior produção: já publicou 14 livros (oito sobre rádio), 35 capítulos em livros diversos e 25 artigos publicados em periódicos. A obra mais recente organizada pela professora é 70 anos de radiojornalismo no Brasil - 1941/2011 (2011). Coordenou o GP Rádio e Mídia Sonora da Intercom em dois períodos: 1994 e depois em 2000-2002.

\section{Considerações finais}

A pesquisa acadêmica sobre rádio no Brasil pode ser considerada recente assim como é a própria implantação do rádio no país, que data do início do século XX. A geração atual de pesquisadores, que encabeçam as listas dos principais livros publicados e trabalhos apresentados em congressos de Comunicação Social, reúne ex-profissionais de rádio que seguiram carreira acadêmica e transformaram o meio, antes referência profissional para eles, em objeto de estudo. Obviamente, associados a esses, estão professores e pesquisadores que se encantaram pelo rádio na própria academia.

Vários exemplos podem ser citados. Apenas nos nove encontros realizados pela SBPJor, foram apresentados 44 trabalhos, escritos por 33 pesquisadores de diferentes instituições do Brasil, que tiveram como tema o rádio. $\mathrm{Na}$ pesquisa do Portal Capes, que envolve um período de 23 anos, de 1987 a 2010, foram publicadas um total de 125 teses e 486 pesquisas realizadas em nível de mestrado, em todo o país, em diferentes programas de 
várias universidades. As maiores produções ocorreram nos últimos três anos. O que demonstra que o rádio é sim um objeto de estudo importante dentro da academia por causa de sua importância junto à sociedade. $\mathrm{O}$ rádio é, sem dúvida, o meio de comunicação que mais evoluiu nas últimas décadas em função das novas tecnologias. Por causa da internet, o rádio teve que se adaptar à nova realidade, renovando as linguagens existentes e ganhou mais espaço porque pode ser transmitido e ouvido por outras plataformas como celular, iPod, computadores domésticos e de mão. Por isto tudo, suscita mais pesquisas científicas e os teóricos e pesquisadores têm acompanhado essas mudanças com a atenção devida.

O trabalho desses professores-pesquisadores contribui para reverter a lógica do mercado profissional no qual o rádio, valendo-nos aqui de um clichê, é considerado metaforicamente o "primo pobre da TV" ou o "patinho feio" no imenso lago midiático. Mais do que a iniciativa isolada de um ou outro pesquisador, destaca-se o esforço coletivo de um grupo que transita em pesquisas conjuntas e entidades distintas, por vezes reunindo dezenas de profissionais em projetos temáticos sobre o rádio.

\section{Referências bibliográficas:}

HAUSSEN, Doris. A producão científica sobre o rádio no Brasil: livros, artigos, dissertações e teses (1991-2001). In Revista Famecos, EDIPUCRS. Porto Alegre, dezembro de 2004, pág.119 a 126.

MEDITSCH, Eduardo; SEGALA, Mariana. Trends in three 2003/4 Journalism academic meetings. In Revista Brazilian Journalism Research, SBPJOR, 2005, no 1, vol. 1, pág. 48 a 60.

MOREIRA, Sônia Virgínia. Prefácio.In: CUNHA, Mágda Rodrigues da; HAUSSEN, Doris (org.). Rádio brasileiro: episódios e personagens. Porto Alegre: EDIPUCRS, 2003.

MOREIRA, Sônia Virgínia. Trends and new challenges in Journalism Research in Brazil. In Revista Brazilian Journalism Research, SBPJOR, 2005, no 1, vol. 2, pág. 10 a 24.

PRATA, Nair. Grupo de Pesquisa Rádio e Mídia Sonora - 20 anos. Anais do XXXIV Congresso Brasileiro de Ciências da Comunicação. Recife: 2011.

PRATA, Nair; MOURA, Ângela; PESSOA, Sônia; CAMPELO, Wanir; FIALHO, Waldiane. Estudos sobre o rádio na academia - o caso de Belo Horizonte. In: Sonia Virginia Moreira. (Org.). 70 anos de radiojornalismo no Brasil. Rio de Janeiro: EdUERJ, 2011, v. 1, p. 363-376.

\section{Referências eletrônicas:}

Compós: $\underline{\text { http://www.compos.org.br }}$

Intercom: http://www.intercom.org.br

Plataforma Lattes - http://lattes.cnpq.br/.

Portal de Teses da Capes: http://capes.gov.br/servicos/ banco-de-teses

Pós-graduação - ECA - Comunicação - http://www. pos.eca.usp.br/index.php?q=pt-br/node/14.

Pós-Graduação da Eco - http://www.pos.eco.ufrj.br/

Pós-graduação da Pontifícia Universidade Católica de SP: $\underline{\text { http://pos.pucsp.br/ }}$

Rede Alcar: http://paginas.ufrgs.br/alcar/

SBPJor - http://www.sbpjor.org.br

Recebido: 30/09/2013

Aprovado: 29/10/2013 